\title{
Genetic Diversity of Local Cowpea (Vigna spp. (L.) Walp.) Accessions Cultivated in Some Regions of Egypt
}

\author{
Ehab M.B. Mahdy ${ }^{1, *}$, Hossam F.A. El-Shaer ${ }^{2}$, Abd El-Hadi I.H. Sayed ${ }^{2}$ and Abeer El- \\ Halwagi ${ }^{1}$ \\ ${ }^{1}$ National Gene Bank, Agricultural Research Centre (ARC), Giza, Egypt; ${ }^{2}$ Botany Department, Faculty of Agriculture, Al-Azhar University, \\ Cairo, Egypt.
}

Received: August 31, 2020; Revised: January 1, 2021; Accepted: February 4, 2021

\begin{abstract}
This work described the ten cowpea accessions using morphological, agronomical, and molecular characterization and select the desirable cowpea accession for improvement. Twenty-four characteristics were quantitative attributes. Data demonstrated by the Principal Component Analysis (PCA) increasing in some components associated with a decrease in eigenvalues, which gave its max at three factors. The PCA was arranged into three main components, which altogether valued at $63.40 \%$. The matrix of PCA data is standardized. The coordinates were calculated for Bi-plot mapping using the Perceptual Mapping (PERMAP). Radiata accessions (1 and 2) fell into a group. Unguiculata accessions are classified further into two sub-groups. The accessions (4 and 6) dropped into a sub-group, and the rest gathered into another sub-group. The PCR-based marker technique, SSR markers, were also analyzed. These markers gave a total of 64 alleles with $51.32 \%$ of polymorphism. A total of 26 alleles were polymorphic. The most informative markers were EH03, EH09, EH06, and EH07. The SSR-phenogram had classified into two main groups at a distance of 0.34 . The first one comprises accessions 1 and 2. The second fell further into two sub-groups at a distance of 0.52 .
\end{abstract}

KeyWords: Vigna, SSR, SCoT analysis, Principal Component Analysis (PCA), PERMAP Bi-plot mapping.

\section{Introduction:}

Vigna possesses more than 150 species originating especially in Africa and Asia (Maréchal et al. 1978; Norihiko et al. 2010, 2014). Vigna species proliferate in Africa and Asia and grow well below a greater diversity of environmental conditions, including climatic, soil, and cultural features more than most legume crops. They are used as pulses, fodder, and cover crops (Norihiko et al. 2010, 2014; Dachapak et al. 2017; Karuniawan et al. 2006). Having the same uses in Egypt, both species own an excellent protein source, especially the unguiculata than radiata.

For its improvement, acknowledge the nature and magnitude of genetic divergence are essential for the selection of diverse parents for a breeding program to get an abroad sense of gene recombination for quantitatively inherited traits. Agronomical traits play a significant role in studying and characterizing accessions for a long. Molecular marker analysis with morphological and agronomic evaluation data increase the resolving power of genetic diversity analysis and provide complementary information (Shrivastav et al. 2012).
Recently, more sensitive DNA-based techniques like Inter-Simple Sequence Repeat (ISSR), Cleaved Amplified Polymorphic Sequence (CAPS), Simple Sequence Repeats (SSR), and Start Codon Taget (SCot) markers are most suitable because of easiness in handling, reproducibility, multi-allelic nature, codominant inheritance, relative abundance and genomic wide coverage (Powel et al. 1996). The SSRs are groups of short tandem repeated nucleotides scattered in the genome.

SSR markers are a valuable tool for genetic mapping, genotyping and marker-assisted selection in breeding due to their characterization of codominant loci, high allelic variation and even distribution (Hernandez et al. 2002). This technique is becoming the marker of choice because of its high polymorphism and occurrence throughout the genome. Recently, more efforts are devoted to developing SSR markers in various crops. In cowpea SSR analysis, the earliest research was conducted by Li et al., 2001, and twenty-seven primers have developed. Africa is the diversity centre of wild cowpea, as established by Ogunkanmi et al (2008) using SSR analysis.

Start codon targeted (SCoT) polymorphism has recently emerged as a new and promising marker technique for the genetic diversity assessment in plants (Collard and Mackill 2009) due to longer primer sequences

\footnotetext{
* Corresponding author e-mail: ehab.mahdy@arc.sci.eg.

** Abbreviations: SSR= Simple Sequence Repeats; SCoT= Start Codon Target; PCA= Principal Component Analysis; PERMAP Bi-plot= Perceptual Mapping Bi-plot analysis; $\mathrm{Nb}=$ no. of alleles; $\mathrm{MB}=$ no. of monomorphic band; $\mathrm{PB}=$ no. of polymorphic band; $\mathrm{P}=$ polymorphism; PIC= polymorphic information content; $\mathrm{EMR}=$ effective multiplex ratio; $\mathrm{MI}=$ marker index; I= Shannon informative index; $\mathrm{Ho}=$ observed heterozygosity; $\mathrm{He}=$ expected heterozygosity; $\mathrm{uHe}=$ unbiased heterozygosity; $\mathrm{F}=$ fixation index.
} 
and reproducibility. The SCoT marker is designed based on the conserved region surrounding the translation initiation codon, ATG (Sawant et al. 1999). A single primer is used for SCoT to amplify DNA without prior genomic sequence information. The SCoT could directly be used in marker-assisted breeding programs, unlike random markers (Mulpuri et al. 2013). SCoT markers could evaluate fruitfully genetic diversity, genetic structure, cultivar identification, quantitative trait loci (QTL) mapping, and DNA fingerprinting in various crops such as orange (Jiang et al. 2011), date palm (Al-Qurainy et al. 2015), Pistacia species (Amirbakhtiar and Sorkheh 2015), mango (Leo et al. 2011), and jojoba (Heikrujam et al. 2015).

This investigation assessed the genetic diversity of ten cowpea accessions, representing two Vigna species. Vigna radiata and V. unguiculata subspecies cvgroup: unguiculata procured by National Gene Bank of Egypt from different local districts. Morphological and agronomical traits as well as molecular markers are used to select desirable accessions for cowpea improvement.

\section{Materials and Methods}

The viable ten accessions representing two accessions of $V$. radiata and eight of $V$. unguiculata subspecies $c V$ group: unguiculata were procured from local regions (Table 1) by National Gene Bank (NGB), Agricultural Research Centre (ARC), Giza, Egypt. Those selected for this study act as the desirable accessions deposited in NGB, which are more than one hundred accessions of Vigna.

\subsection{Morphological data:}

Experimentations were carried out in the field of National Gene Bank (NGB), Agricultural Research Centre (ARC), Giza, during 2015. The observations follow the standard format descriptor lists for Vigna (IBPGR 1983). The data comes from the mean of the twenty-five healthy mature plant materials for each. The morphological terminology follows Stearn (1973). The herbarium voucher-specimens and clean mature seeds were deposited and stored at the herbarium and storerooms of NGB based on the standard of gene bank (IPGRI, 1994).
Table (1): List of studied accessions of genus Vigna.

\begin{tabular}{lllll}
\hline Code & Taxa & $\begin{array}{l}\text { Accession } \\
\text { No. }\end{array}$ & $\begin{array}{l}\text { Collected } \\
\text { date }\end{array}$ & $\begin{array}{l}\text { Collected } \\
\text { area }\end{array}$ \\
\hline 1 & Vigna radiata & 19538 & 2005 & Giza \\
2 & Varity: radiata & 19537 & 2004 & Giza \\
\hline 3 & & 14176 & 2008 & Dakhla \\
4 & & 13884 & 2008 & Dakahlyia \\
5 & Vigna unguiculata & 101 & 2010 & Luxur \\
6 & Subspecies: & 27301 & 2007 & Sohag \\
7 & unguiculata cv- & 26983 & 2007 & Qena \\
8 & group: unguiculata & 26981 & 2007 & Qena \\
9 & & 26945 & 2007 & Aswan \\
10 & & 26738 & 2006 & Menyia \\
\hline
\end{tabular}

2.2. Genetic variation detected by SSR and SCoT analysis:

Total genomic DNA from $5 g$ of fresh young leaf tissue, collected from five random plants per accession, was extracted following the Zymo Research Kit. Electrophoresis was made on $1 \%$ agarose gel electrophoresis at 100 Volt for $30 \mathrm{~min}$. The total genomic DNA was diluted to $10 \mathrm{ng} / \mu \mathrm{l}$ of PCR analysis. Ten SSR primers representing 11 linkage groups designed previously by Kongjaimun et al. (2012) and Wang et al. (2004) and 17-SCoT primers chosen from Collard and Mackill (2009) of Vigna species under study evaluated as shown in Table 2. The PCR reactions perform in a $20 \mu \mathrm{l}$ reaction mixture containing $10 \mathrm{ng}$ template DNA, $200 \mu \mathrm{M}$ dNTPs, $250 \mathrm{nM}$ of each primer, $1.5 \mathrm{mM} \mathrm{MgCl2,} \mathrm{1x} \mathrm{PCR}$ buffer, and 1unit Taq DNA polymerase. The PCR amplification was performed with an initial denaturation at $94^{\circ} \mathrm{C}$ for 5 min followed by 35 cycles of $94^{\circ} \mathrm{C}$ for $1 \mathrm{~min}$, 50 to $60^{\circ} \mathrm{C}$ (depending on the primer, see Table 2) for 1 min, $72^{\circ} \mathrm{C}$ for $2 \mathrm{~min}$, and a final extension at $72^{\circ} \mathrm{C}$ for 5 min before cooling at $4^{\circ} \mathrm{C}$ (Collard and Mackill, 2009; Kongjaimun et al., 2012).

Each amplicon profile is defined by the presence (1) or absence $(0)$ of bands based on the band positions relative to the ladder sequentially from the smallest to the largestsized bands. Band profiles are variable when identifying one polymorphic band, at least. Fragments were scored as 1 if present or 0 if absent based on standard marker using Alpha Ease FCTM (version 4.0.1) software. The cluster analysis was computed as the Un-weighted Pair-group Method with Arithmetic averages (UPGMA) method to generate a dendrogram for studying the relationship among accessions based on Nei and Li (1979). Unique alleles defined as those were detected in only one species. A binary matrix was then transformed into genetic similarity (GS) matrices using Jaccard's coefficient (Jaccard, 1908). 
Table (2): Sequences of SSR and SCoT markers used for Vigna accessions under study.

\begin{tabular}{|c|c|c|c|c|c|c|}
\hline Code & Marker & \multicolumn{4}{|l|}{ Primer sequence } & $\mathrm{Tm}$ \\
\hline \multicolumn{7}{|c|}{ SSR Primer: } \\
\hline Eh01 & CEDG088 & \multicolumn{2}{|c|}{ F: TCTTGTCATTTAGCACTTAGCACG } & \multicolumn{2}{|c|}{ R: TTGTTGTTTACTAAGAGCCCGTGT } & 60 \\
\hline Eh02 & CEDG086 & \multicolumn{2}{|c|}{ F: GAGTTTACAACAGATGGGGCTAA } & \multicolumn{2}{|c|}{ R: AGGTCTTGATTGACTTTCTGGGT } & 60 \\
\hline Eh03 & CEDG073 & \multicolumn{2}{|c|}{ F: GGTTAGCATCTGAGCTTCTTCGTC } & \multicolumn{2}{|c|}{ R: AACACCCGCCTCTTTCTCC } & 60 \\
\hline Eh04 & CEDG044 & \multicolumn{2}{|c|}{ F: TCAGCAACCTTGCATTGCAG } & \multicolumn{2}{|c|}{ R: TTTCCCGTCACTCTTCTAGG } & 57 \\
\hline Eh05 & CEDG056 & \multicolumn{2}{|c|}{ F: TTCCATCTATAGGGGAAGGGAG } & \multicolumn{2}{|c|}{ R: GCTATGATGGAAGAGGGCATGG } & 60 \\
\hline Eh06 & CEDG006 & \multicolumn{2}{|c|}{ F: AATTGCTCTCGAACCAGCTC } & \multicolumn{2}{|c|}{ R: GGTGTACAAGTGTGTGCAAG } & 57 \\
\hline Eh07 & CEDG014 & \multicolumn{2}{|c|}{ F: GCTTGCATCACCCATGATTC } & \multicolumn{2}{|c|}{ R: AAGTGATACGGTCTGGTTCC } & 57 \\
\hline Eh08 & CEDG013 & \multicolumn{2}{|c|}{ F: CGTTCGAGTTTCTTCGATCG } & \multicolumn{2}{|c|}{ R: ACCATCCATCCATTCGCATC } & 57 \\
\hline Eh09 & CEDG010 & \multicolumn{2}{|c|}{ F: TGGGCTACCAACTTTTCCTC } & \multicolumn{2}{|c|}{ R: TGAGCGACATCTTCAACACG } & 57 \\
\hline Eh10 & FER & \multicolumn{2}{|c|}{ F: TCGCAAAGTTGCCAGTCAGT } & \multicolumn{2}{|c|}{ R: TAGAAGGAAGGAGGGCATG } & 42 \\
\hline \multicolumn{7}{|c|}{ SCoT Primers: } \\
\hline S01 & SCoT-02 & ACCATGGCTACCACCGGC & $\mathrm{S} 10$ & SCoT-14 & ACCATGGCTACCAGCGCG & \\
\hline S02 & SCoT-03 & ACGACATGGCGACCCACA & $\mathrm{S} 11$ & SCoT-16 & CCATGGCTACCACCGGCA & \\
\hline S03 & SCoT-04 & ACCATGGCTACCACCGCA & $\mathrm{S} 12$ & SCoT-24 & CCATGGCTACCACCGCAG & \\
\hline S04 & SCoT-05 & CAATGGCTACCACTAGCG & $\mathrm{S} 13$ & SCoT-28 & CAACAATGGCTACCACCA & \\
\hline S05 & SCoT-06 & CAATGGCTACCACTACAG & $\mathrm{S} 14$ & SCoT-34 & ACGACATGGCGACCAACG & \\
\hline S06 & SCoT-09 & ACAATGGCTACCACTGCC & $\mathrm{S} 15$ & SCoT-35 & AACCATGGCTACCACCAC & \\
\hline S07 & SCoT-11 & ACAATGGCTACCACTACC & $\mathrm{S} 16$ & SCoT-45 & ACCATGGCTACCACCGAG & \\
\hline S08 & SCoT-12 & CAACAATGGCTACCACCG & $\mathrm{S} 17$ & SCoT-48 & CACCATGGCTACCACCAG & \\
\hline S09 & SCoT-13 & ACCATGGCTACCACGGCA & & & & \\
\hline
\end{tabular}

\subsection{Statistical analysis}

The averages and standard errors were calculated for all morphological attributes. The Principal Component Analysis (PCA) calculates for morphological attributes was based on Johnson (1998). The data matrix of linkage among accessions and morphological attributes were standardized. The coordinates estimate for Bi-plot mapping is based on the perceptual mapping (PERMAP).

Polymorphism information content (PIC) values were calculated by Anderson et al. (1993) based on the formula: $P I C=1-\sum P_{i}^{2} \quad$ for co-dominant marker and PIC $=1-p^{2}-q^{2}$ for dominant marker; where: $P_{i}$ is the frequency of the $i^{\text {th }}$ alleles, and $q$ is the null allele frequency. The resolving power (Rp) for each primer was calculated as $R p=\Sigma I_{b}$ where: $I_{b}$ (band informativeness) takes the value: $I_{b}=1-(2 \times(0.5-p))$ and $p$ is the proportion of the genotype of different Vigna accessions containing that band (Prevost and Wilkinson, 1999). The Marker Index (MI) calculates according to Varshney et al. (2007) as per the following formula: $M I=P I C \times E M R$, where $E M R$ (Effective multiplex ratio) $=\mathrm{n} \beta$, where: $\mathrm{n}$ is he average number of fragments amplified by accession to a specific system marker (multiplex ratio) and, $\beta$ is the number of polymorphic loci (PB) and the number of non-polymorphic loci (MB); $\beta=\mathrm{PB} /(\mathrm{PB}+\mathrm{MB})$.

Data sets derived from all averages of attributes were fed into SPSS (version. 14.0) and StatistiXL adding in Microsoft Excel (Kovach Computing Service, 2013, version. 1.8) Program, as well as conducted on GenAlEx (Peakall and Smouse, 2006).

\section{Results and Discussion}

\subsection{Diversity revealed by morphological attributes}

\subsubsection{Morphological characterization:}

Vigna radiata (L.) R. Wilcz. variety radiata

An annual herb, erect or sub-erect, up to $50 \mathrm{~cm}$. stems bristly hairy. Leaves trifoliolate, leaflets elongate-ovate, Flowers pale yellow $1.7-2.0 \mathrm{~cm}$ long. Pods horizontal, linear-cylindric, 4-10 $\mathrm{cm}$ long and 4-6 mm broad, with a dark brown, short, spreading, bristly indument; the 9-12 seeds are greenish to brown, oblong-cylindric to subglobose (Rhomboid), 4.2-4.9 x 3.2-3-8 mm.

Two accessions ( 1 and 2 ) were accessed from the National gene bank of Egypt. For more details of morphological attributes, see Table (3 and 4) and plate (1, 2, and 3).

Vigna unguiculata (L.) Walp. subspecies unguiculata cv-group unguiculata E.Westphal

Annual herb, erect or sub-erect, spreading, up to 200 $\mathrm{cm}$ tall, glabrous. Stems usually procumbent, often tinged with purple. Leaves are trifoliolate and alternate. The terminal leaflet is often bigger and longer than the two asymmetrical laterals. Leaflets are ovoid-rhombic, entirely or slightly lobed, apex acute, 7.5-15 cm long, 5-11 cm wide. Petiole, stout, grooved, $7-15 \mathrm{~cm}$ long. The inflorescence is axillary; peduncles are $2.5-15 \mathrm{~cm}$ long. Flowers are white, cream, yellow, and calyx campanulate with triangular teeth; the upper two teeth are connate and longer than the rest. Corona is dull-white, yellow, or violet with standard $2-3 \mathrm{~cm}$ in diameter and keel truncate. Pods are curved, straight, 8-20 cm long with 8-14 seeds/pod. Seeds 5-10 mm long, 4-7mm width, globular to reniform, 
smooth or wrinkled, brown, green buff or white, as dominant color; full-colored, spotted, marbled, speckled, eyed, or blotched.

A total of the rest, eight accessions were accessed from National Gene Bank. For more details of morphological attributes, see Table (3 and 4) and plate (1, 2, and 3).

Soliman et al. (2008) reported that the plant hairiness, flower color, pod wall thickness, cotyledon color, seed color, eye pattern and color, seed turgidity, and seed crowding are the most significant morphological attributes
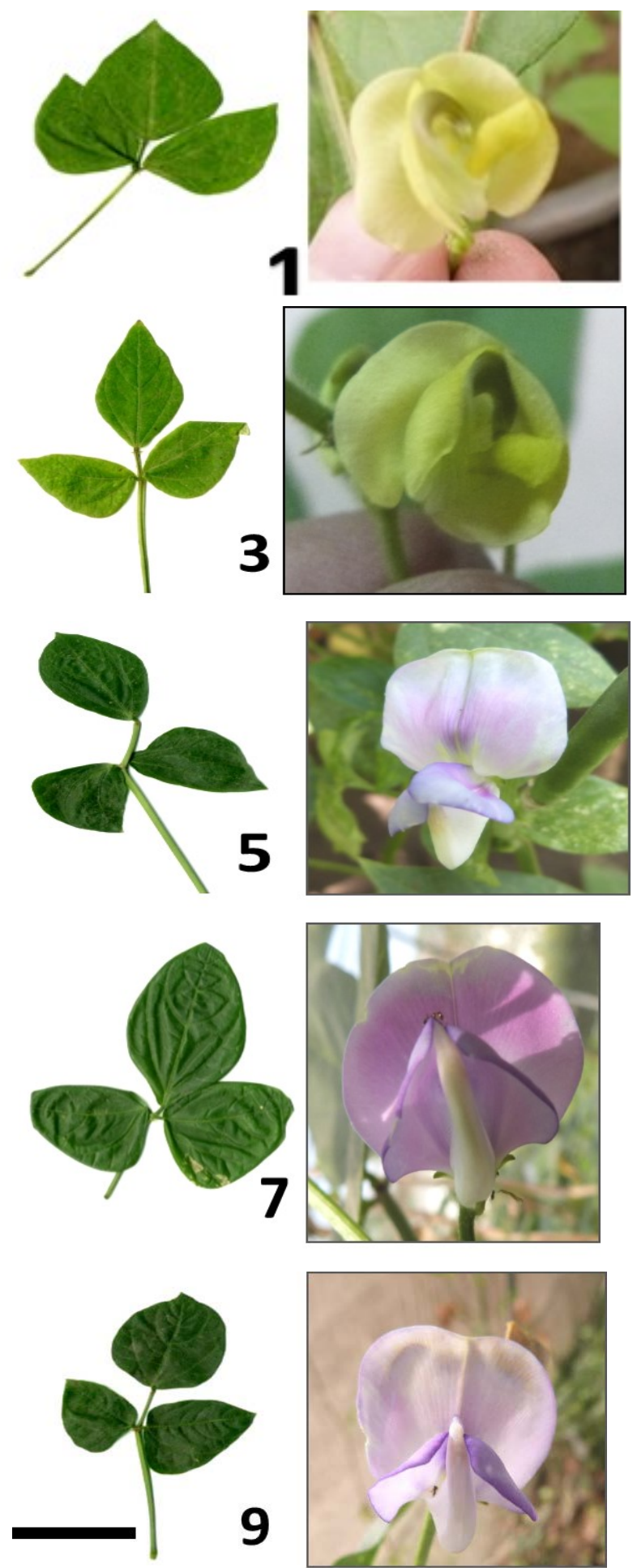

\footnotetext{
Plate (1): Leaf and flower shapes of the studied accessions of cowpea. For accession name, see table (1). The scale bar equals $15 \mathrm{~cm}$.
}

to distinguish among subgenera. The type of germination, the thigmotropic movements of hypocotyl and the stem, seedling architecture, and plant longevity were recorded by Ojeda et al. (2013) on four species of Vigna Savi. These characteristics permitted us to distinguish the species and construct an identification key that could be useful for agronomic or floricultural purposes. Selvakumar and Kumari (2015) reported that the color of seeds is differed subsequent generations due to the different gene actions, which confirm a further progeny.
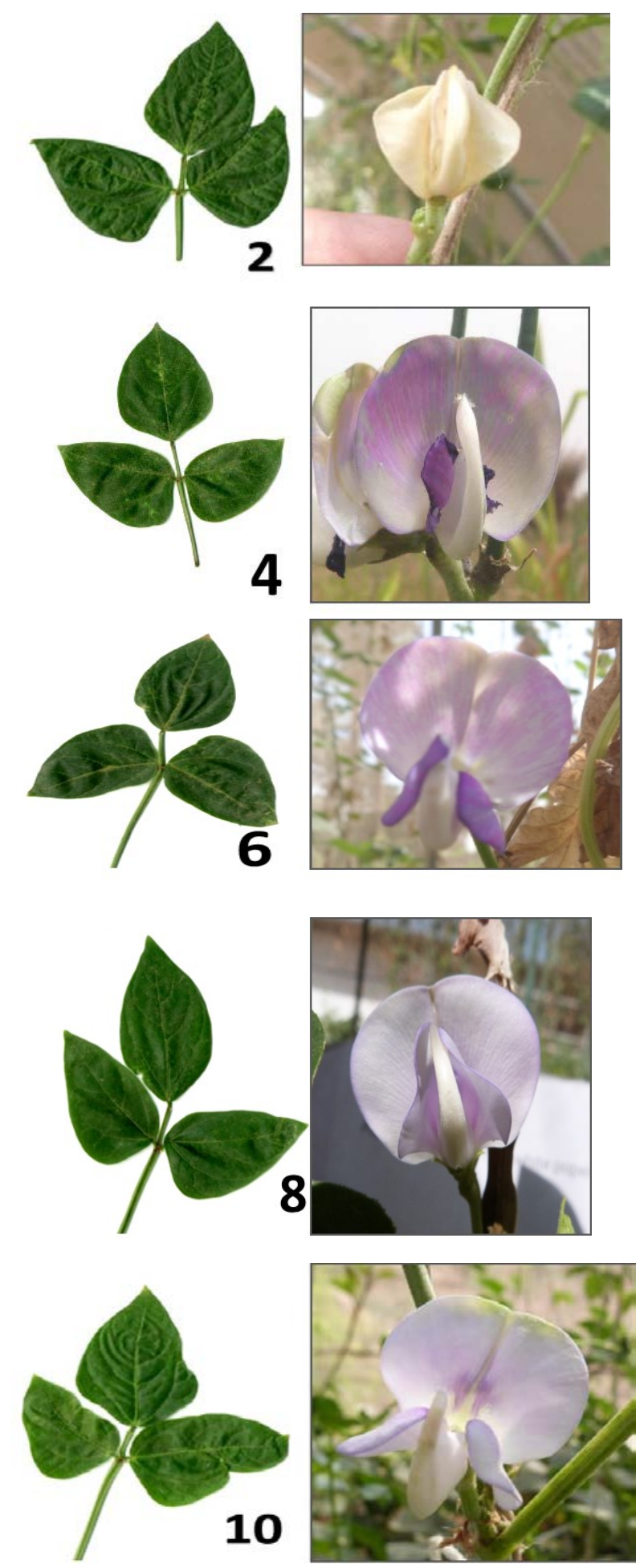


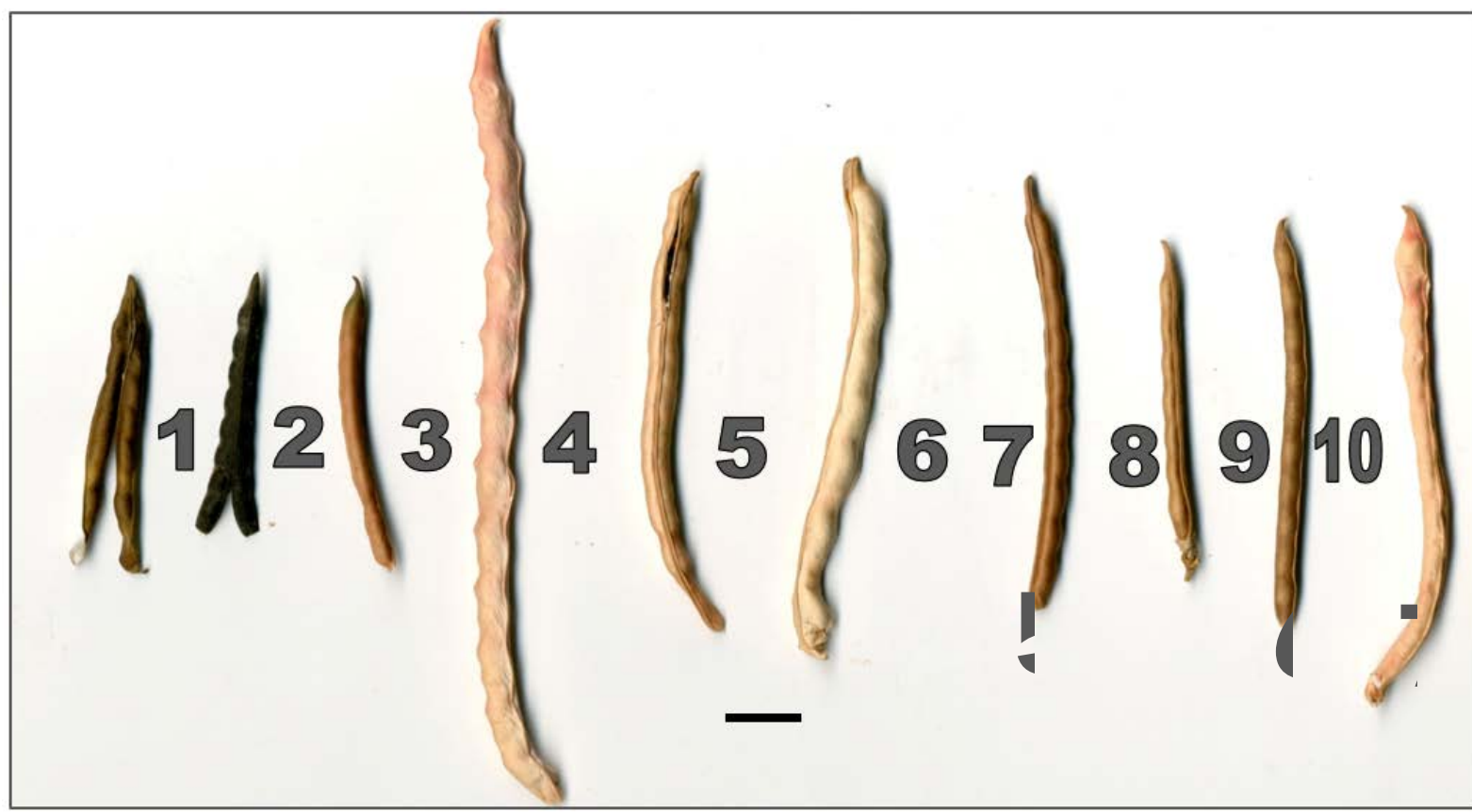

Plate (2): Pods of the studied accessions of Vigna. For accession name, see table (1). The scale bar equals $1 \mathrm{~cm}$.

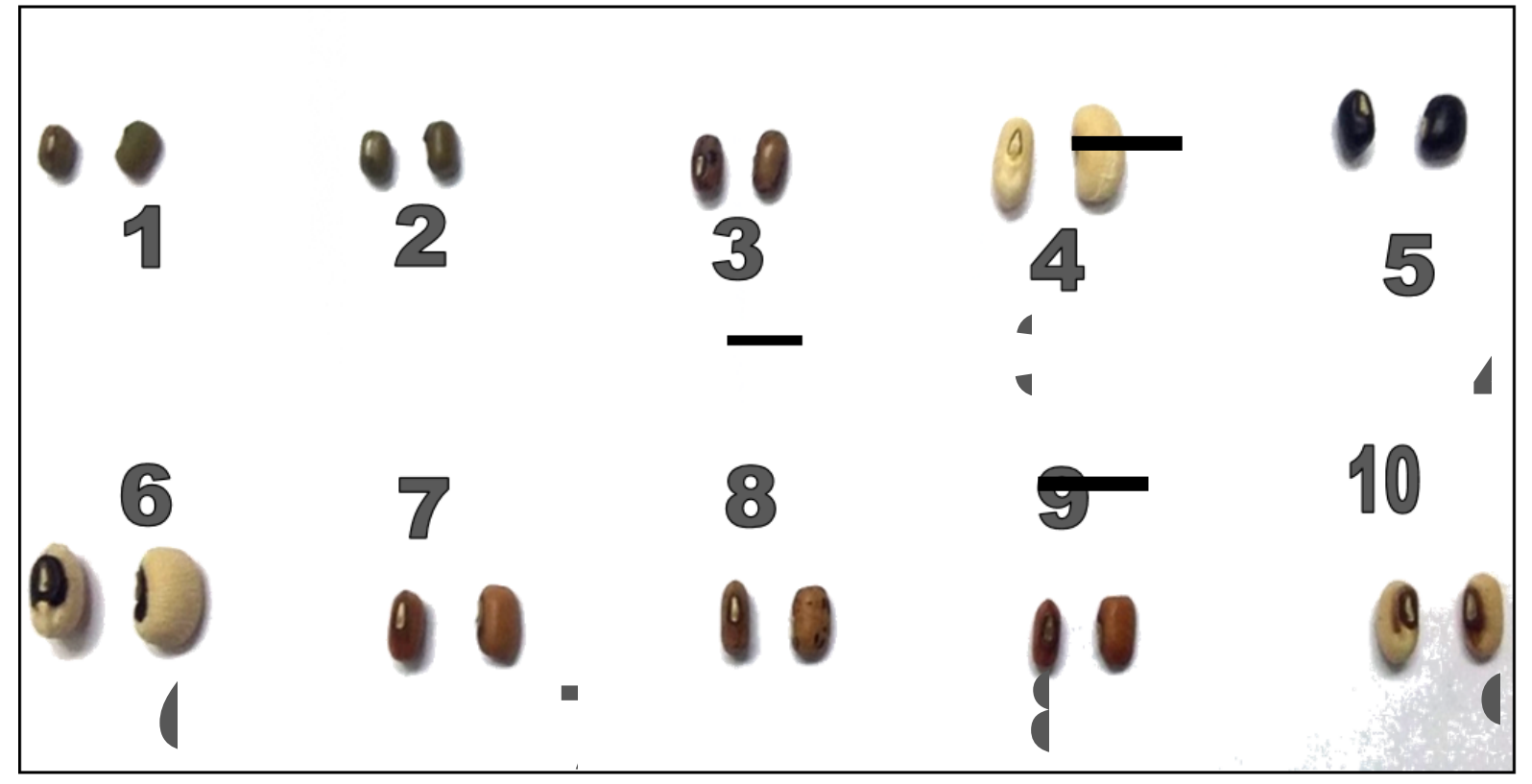

Plate (3): Seeds of the studied accessions of Vigna. For accession name, see table (1). The scale bar equals $1 \mathrm{~m}$ 
Table (3): Morphological characters of the studied accessions of Vigna. For accession ID, See table 1.

\begin{tabular}{|c|c|c|c|c|c|c|c|c|c|c|c|}
\hline & Accession ID & 1 & 2 & 3 & 4 & 5 & 6 & 7 & 8 & 9 & 10 \\
\hline Code & Characteristics & & & & & & & & & & \\
\hline 1 & Growth habit (1.Erect; 2.Prostrate; 3.Climbing) & 3 & 3 & 3 & 3 & 3 & 3 & 3 & 3 & 3 & 1 \\
\hline 2 & Growth Pattern (1.Determine; 2.Indetermine) & 2 & 2 & 2 & 2 & 2 & 2 & 2 & 2 & 2 & 2 \\
\hline 3 & Twinning tendancy (0.None; 3.Slight; 5.Intermediate; 7.Pronounced) & 3 & 3 & 7 & 7 & 7 & 5 & 5 & 3 & 7 & 7 \\
\hline 4 & Plant pigmentation (0.None; 3.Slight; 5.Intermediate; 7.Extensive; 9.Solid) & 0 & 0 & 3 & 0 & 0 & 0 & 0 & 3 & 0 & 0 \\
\hline 5 & Plant hairiness (3.Glabrescent; 5.Short appressed hairs; 7.Pubscent to hirsute) & 7 & 7 & 3 & 3 & 3 & 3 & 3 & 3 & 3 & 3 \\
\hline 6 & Plant vigor (3.Non-vigorous; 5.Intermediate; 7.Vigorous; 9.Very vigorous) & 3 & 3 & 9 & 9 & 9 & 9 & 9 & 7 & 7 & 9 \\
\hline 7 & Leaf color (3.Pale green; 5.Intermediate; 7.Dark green) & 7 & 7 & 7 & 7 & 7 & 7 & 7 & 7 & 7 & 7 \\
\hline 8 & $\begin{array}{l}\text { Terminal leaflet shape (1.Deltoid; 2.Ovate; 3.Ovate-Lanceolate; 4.Acute; } \\
\text { 5.Cuneate; 6.Lobed) }\end{array}$ & 2 & 1 & 2 & 2 & 3 & 1 & 5 & 2 & 2 & 5 \\
\hline 9 & Leaf marking (0.Absent; 1.Present) & 0 & 0 & 0 & 0 & 0 & 0 & 0 & 0 & 0 & 0 \\
\hline 10 & Leaf texture (1.Cariaceous; 2.Intermediate; 3.Membranous) & 3 & 3 & 3 & 3 & 3 & 3 & 3 & 3 & 3 & 3 \\
\hline 11 & $\begin{array}{l}\text { Flowering pigment pattern (0.White; } 1 \text {.Wing pigmented, standard with V- } \\
\text { shaped; 2.Pigmented margins on wing; 3.Pigmented, standard slightly } \\
\text { pigmented; 4.wing with pigmented upper margins; 5.completely pigmented) }\end{array}$ & 1 & 1 & 1 & 1 & 1 & 1 & 1 & 1 & 1 & 1 \\
\hline 12 & $\begin{array}{l}\text { Raceme position (1.Mostly above canopy; 2.In upper canopy; 3.Throughout } \\
\text { canopy) }\end{array}$ & 1 & 1 & 1 & 1 & 3 & 1 & 3 & 1 & 3 & 1 \\
\hline 13 & Flower color (1.White; 2.Violet; 3.Mauve-pink; 4.Purple; 5.Yellow) & 5 & 5 & 3 & 3 & 3 & 3 & 3 & 3 & 3 & 5 \\
\hline 14 & Pod attachment to peduncle (3.Pendant; 5.30-90 down from erect; 7.Erect) & 7 & 7 & 5 & 7 & 5 & 7 & 7 & 7 & 7 & 5 \\
\hline 15 & $\begin{array}{l}\text { Immature pod pigmentation (0.None; } 1 \text {. Pigmented tip; 2.Pigmented Sutures; } \\
\text { 3.Pigmented Valves, green Sutures; } 4 \text {.Splashes of Pigment; } 5 . \text { Uniformly } \\
\text { pigmented) }\end{array}$ & 0 & 0 & 0 & 0 & 0 & 0 & 0 & 0 & 0 & 0 \\
\hline 16 & Pod curvature (0.Straight; 3.Slightly straight; 5.Curved; 7.Coiled) & 3 & 3 & 3 & 3 & 3 & 3 & 3 & 3 & 3 & 3 \\
\hline 17 & Number of pods per peduncle & 2 & 2 & 2 & 2 & 2 & 2 & 2 & 2 & 2 & 2 \\
\hline 18 & Seed crowding (0.None; 3.Semi-crowded; 5.Crowded; 7.Extremely crowded) & 0 & 0 & 0 & 3 & 0 & 3 & 0 & 0 & 0 & 0 \\
\hline 19 & Seed shape (1.Kidney; 2.Ovoid; 3. Crowder; 4.Globose; 5.Rhomboid) & 5 & 5 & 5 & 1 & 5 & 1 & 5 & 5 & 5 & 1 \\
\hline 20 & $\begin{array}{l}\text { Seed color (1.White; 2.Cream; 3.Brown splash or grey; 4.Chocolate; 5.Red; } \\
\text { 6.Green; 7.Black; 8.Mottled and speckled; 9.Other) }\end{array}$ & 6 & 6 & 8 & 2 & 7 & 1 & 5 & 8 & 5 & 2 \\
\hline 21 & $\begin{array}{l}\text { Testa pattern (0.No pattern; 1.Entire line; 2.Striped; 3.Marbled; 4.Dotted; } \\
\text { 5.Little rhomboid spotting only on one side of hilum; 6.Little romboid spotting } \\
\text { on both sides of hilum; 7.Much rhomboid spotting on both sides of hilum; } \\
\text { 8.Holestein pattern) }\end{array}$ & 0 & 0 & 3 & 0 & 0 & 0 & 0 & 1 & 0 & 0 \\
\hline 22 & $\begin{array}{l}\text { Testa texture (1.Smooth; 3.Smooth to rough; 5.Rough (fine reticulation); } \\
\text { 7.Rough to wrinkled; 9.Wrinkled (coarse folds on the testa)) }\end{array}$ & 1 & 1 & 1 & 1 & 1 & 9 & 1 & 1 & 1 & 1 \\
\hline 23 & $\begin{array}{l}\text { Eye pattern (0.No eye; } 1 \text {.Eye as a thin circle around hilum; } 2 \text {.Eye as } 2 \text { thin } \\
\text { lines on both sides of hilum; } 3 \text {.Eye as } 2 \text { thick lines on both sides of hilum; } \\
\text { 4.Eye forms almost triangular shape; } 5 \text {.Large eye, more or less shapeless, } \\
\text { becoming frayed; } 6 \text {.Eye like a butterfly; } 7 \text {.Mottled eye) }\end{array}$ & 1 & 1 & 1 & 1 & 0 & 3 & 1 & 1 & 1 & 3 \\
\hline 24 & $\begin{array}{l}\text { Eye color (0.Eye absent (white, cream); } 1 \text {.Brown splash or grey; } 2 \text {.Tan brown; } \\
\text { 3.Red; 4.Green; 5.Blue to Black; 6.Blue to black spots or mottle; } 7 . \text { Speckled; } \\
\text { 8.Mottled; 9.Mottled and speckled; } 10 . \text { Other) }\end{array}$ & 1 & 1 & 5 & 0 & 5 & 5 & 5 & 5 & 5 & 1 \\
\hline 25 & Splitting of testa (0.Absent; 1.Present) & 0 & 0 & 0 & 0 & 0 & 0 & 0 & 0 & 0 & 0 \\
\hline 26 & $\begin{array}{l}\text { Attachment of testa (0.Testa not firmly attached to seed; } 1 \text {.Testa firmly } \\
\text { attached to seed) }\end{array}$ & 1 & 1 & 1 & 1 & 1 & 1 & 1 & 1 & 1 & 1 \\
\hline
\end{tabular}


Table (4): Morphological characters of the studied accessions of Vigna.

\begin{tabular}{|c|c|c|c|c|c|c|c|c|c|c|c|}
\hline Code & Characteristics & 1 & 2 & 3 & 4 & 5 & 6 & 7 & 8 & 9 & 10 \\
\hline 27 & Plant Height $(\mathrm{cm})$ & 37.5 & 39 & 134 & 137 & 62.7 & 107 & 115 & 48 & 45 & 204 \\
\hline 28 & Number of main branches & 3.67 & 3.5 & 3.33 & 2.67 & 3.17 & 3.17 & 3 & 3 & 2.8 & 3 \\
\hline 29 & Terminal leaflet length & 11.7 & 11.7 & 10.7 & 10.2 & 8.06 & 17.2 & 12.4 & 11 & 14 & 15.1 \\
\hline 30 & Terminal leaflet width & 5.82 & 6.31 & 3.98 & 5.15 & 4.99 & 5.73 & 4.39 & 3.6 & 3.8 & 4.48 \\
\hline 31 & Terminal leaflet ratio (length/width) & 2 & 1.85 & 2.68 & 1.98 & 1.62 & 3.01 & 2.83 & 3.1 & 3.6 & 3.38 \\
\hline 32 & Stipule length & 6.99 & 6.34 & 6.02 & 3.08 & 3.39 & 7.01 & 4.99 & 6 & 4.4 & 3.52 \\
\hline 33 & Stipule width & 3.9 & 3.28 & 2.92 & 0.92 & 2.18 & 3.53 & 3.3 & 2.8 & 2.9 & 1.99 \\
\hline 34 & Stipule ratio (length/width) & 1.79 & 1.93 & 2.06 & 3.36 & 1.56 & 1.99 & 1.51 & 2.1 & 1.5 & 1.77 \\
\hline 35 & Days to flowering (week) & 8 & 8 & 7 & 8 & 8 & 9 & 8 & 9 & 10 & 10 \\
\hline 36 & Days to first pods (after flowering) & 7.33 & 10 & 9.83 & 9.5 & 7.17 & 9.5 & 9.83 & 10 & 6.8 & 10.2 \\
\hline 37 & No. of flowers per plant & 19.2 & 18.2 & 25.8 & 21.2 & 14.5 & 20 & 22.2 & 18.8 & 20.2 & 23.3 \\
\hline 38 & Standard length & 0.96 & 1.93 & 1.95 & 1.98 & 2.07 & 2.04 & 1.97 & 2 & 2.2 & 1.92 \\
\hline 39 & Number of pods per plant & 17.3 & 14.2 & 22.7 & 16 & 13.2 & 18 & 19.8 & 18 & 19 & 21.2 \\
\hline 40 & Pods: Flower ratio & 0.9 & 0.78 & 0.88 & 0.76 & 0.91 & 0.9 & 0.89 & 0.9 & 0.9 & 0.91 \\
\hline 41 & Pod Length & 9.75 & 7.8 & 7.7 & 18.4 & 11.1 & 15.4 & 10.4 & 9.15 & 10.7 & 10.6 \\
\hline 42 & No. of seeds / pod & 10.2 & 9.7 & 10.8 & 12.2 & 10.8 & 11.3 & 10.7 & 8.9 & 11.2 & 11 \\
\hline 43 & seed density (seeds no./cm) & 1.05 & 1.24 & 1.4 & 0.66 & 0.98 & 0.73 & 1.03 & 0.97 & 1.04 & 1.03 \\
\hline 44 & Seed length (cm) & 0.48 & 0.48 & 0.61 & 0.87 & 0.5 & 0.92 & 0.68 & 0.66 & 0.68 & 0.79 \\
\hline 45 & Seed width $(\mathrm{cm})$ & 0.38 & 0.37 & 0.42 & 0.54 & 0.41 & 0.66 & 0.45 & 0.44 & 0.46 & 0.57 \\
\hline 46 & Seed thickness (mm) & 2.9 & 3.1 & 2.5 & 4 & 2.3 & 4.1 & 3 & 2.7 & 2.4 & 3.5 \\
\hline 47 & Seeds shape ratio (length/width) & 1.26 & 1.3 & 1.45 & 1.61 & 1.22 & 1.39 & 1.51 & 1.5 & 1.48 & 1.39 \\
\hline 48 & weight of 100 seeds (gm) & 4.33 & 3.93 & 6.5 & 14.5 & 12.1 & 18.2 & 5.24 & 4.8 & 5.78 & 12.4 \\
\hline
\end{tabular}

\subsubsection{Principal Component Analysis (PCA)}

Data presented in Table (5) demonstrated that an increase in the number of components (PC) was associated with a decrease in eigenvalues. This trend reached its maximum at three factors. Accordingly, it is reasonable to assume that the PCA had grouped the estimated variables into three main components, which all accounted for 63.4 $\%$ of the total variation of attributes.

The results showed that PC1 correlates well with the attributes of the weight of 100 seeds, Seed thickness, Seed width, seed length, No. of seeds/pod, pod length, pod attachment to the peduncle, plant height, and plant hairiness. Meanwhile, the PC2 correlates well with the attributes of terminal leaflet width and the number of main branches. The PC3 correlates well with eye pattern, terminal leaflet length, terminal leaflet ratio no. of pods/plant, stipule width, and growth habit. Variables that significantly correlated with the first three eigenvectors were the variables with great variability. Data show that PC1 accounted for about $31.65 \%$ of the variance among attributes; PC2 for $18.21 \%$, and PC3 for $13.54 \%$. Therefore, the traits of seed are the weight of 100 -seeds, seed thickness, seed width and length, and the number of seeds per pod, following the attribute pod Length, terminal leaflet width, and length, plant height, plant hairiness, eye pattern, pod attachment to peduncle showed to affect the significant grain yield characters.

The factor loading is the coefficient of PCs or the correlation between the component and the variables. This correlation indicates that the variables are associated directly with the maximum of variation thru the data set. A similar result, Yin et al. (2002), reported that the wheat grain yield could be classified into three key components.

The main reason for plant collection is to obtain raw materials that increase useful gene pools for crop improvement. According to Johnson (1998), PCA is a more useful statistical tool for screening multivariate data with significantly high correlations. PCA data assists the breeders to identify limited traits for use in hybridization and selection programs. 
Table (5): Loading factor and Eigenvalue of the correlation matrix for the estimated variables of Vigna under study using the PCA.

\begin{tabular}{|c|c|c|c|c|c|c|c|c|c|}
\hline Attributes & $\mathrm{PC}_{1}$ & $\mathrm{PC}_{2}$ & $\mathrm{PC}_{3}$ & $\mathrm{PC}_{4}$ & $\mathrm{PC}_{5}$ & $\mathrm{PC}_{6}$ & $\mathrm{PC}_{7}$ & $\mathrm{PC}_{8}$ & $\mathrm{PC}_{9}$ \\
\hline Growth habit & 0.54 & -0.51 & -0.35 & -0.10 & -0.30 & -0.30 & 0.14 & -0.27 & 0.22 \\
\hline Twinning tendency & -0.26 & -0.52 & 0.04 & 0.62 & 0.32 & 0.08 & -0.35 & -0.13 & -0.16 \\
\hline Plant pigmentation & -0.64 & 0.69 & 0.21 & 0.06 & -0.20 & 0.09 & 0.11 & -0.06 & 0.09 \\
\hline Plant hairiness & 0.69 & -0.57 & -0.24 & 0.04 & 0.06 & -0.30 & -0.03 & 0.17 & -0.08 \\
\hline Plant vigor & 0.20 & -0.49 & 0.14 & -0.20 & -0.57 & 0.01 & 0.21 & 0.45 & -0.30 \\
\hline Terminal leaflet shape & 0.44 & -0.12 & 0.48 & -0.57 & -0.03 & 0.38 & -0.22 & -0.20 & 0.05 \\
\hline Days to flowering & -0.13 & -0.45 & -0.32 & -0.71 & 0.06 & -0.06 & 0.33 & 0.22 & 0.10 \\
\hline Raceme position & -0.29 & 0.49 & 0.51 & 0.03 & -0.64 & 0.09 & -0.04 & -0.05 & 0.05 \\
\hline Flower color & -0.02 & 0.51 & 0.02 & -0.11 & 0.54 & 0.59 & 0.28 & 0.11 & -0.05 \\
\hline Pod attachment to peduncle & 0.73 & 0.48 & -0.26 & 0.17 & 0.34 & -0.11 & 0.03 & -0.06 & -0.02 \\
\hline Seed shape & -0.91 & -0.31 & -0.10 & -0.12 & 0.17 & 0.08 & 0.12 & 0.05 & 0.04 \\
\hline Seed color & -0.86 & -0.40 & -0.17 & 0.14 & 0.11 & 0.02 & -0.17 & -0.03 & -0.07 \\
\hline Testa pattern & -0.23 & -0.54 & 0.00 & 0.72 & 0.18 & -0.21 & -0.07 & -0.22 & 0.06 \\
\hline Testa texture & 0.48 & 0.35 & 0.31 & -0.06 & 0.59 & -0.44 & -0.08 & 0.05 & 0.07 \\
\hline Eye pattern & 0.66 & 0.16 & 0.72 & 0.09 & -0.02 & -0.10 & -0.08 & 0.01 & 0.05 \\
\hline Eye color & -0.11 & -0.64 & 0.03 & -0.23 & 0.65 & -0.29 & -0.05 & 0.14 & 0.02 \\
\hline Plant Height & 0.71 & -0.27 & 0.15 & 0.36 & -0.45 & -0.19 & 0.07 & 0.14 & -0.03 \\
\hline No. of main branches & -0.71 & 0.39 & 0.36 & 0.19 & -0.06 & -0.42 & 0.01 & -0.02 & -0.02 \\
\hline Terminal leaflet length & 0.52 & 0.13 & 0.76 & -0.14 & 0.22 & 0.01 & 0.15 & -0.02 & 0.18 \\
\hline Terminal leaflet width & -0.10 & 0.92 & 0.00 & -0.02 & -0.12 & -0.29 & 0.05 & 0.12 & 0.16 \\
\hline Terminal leaflet ratio & 0.41 & -0.54 & 0.60 & -0.11 & 0.24 & 0.30 & 0.05 & -0.12 & 0.06 \\
\hline Stipule length & -0.44 & 0.33 & 0.53 & 0.30 & 0.55 & -0.13 & 0.06 & 0.00 & -0.03 \\
\hline Stipule width & -0.55 & 0.15 & 0.60 & -0.08 & 0.44 & -0.18 & 0.26 & 0.10 & 0.00 \\
\hline Stipule ratio & 0.44 & 0.35 & -0.50 & 0.56 & 0.00 & 0.26 & -0.10 & -0.17 & -0.10 \\
\hline Days to flowering & 0.44 & -0.12 & 0.48 & -0.57 & -0.03 & 0.38 & -0.22 & -0.20 & 0.05 \\
\hline Days to first pods & 0.31 & -0.02 & 0.24 & 0.68 & -0.05 & 0.17 & -0.23 & 0.53 & 0.11 \\
\hline No. of flowers/plant & 0.34 & -0.39 & 0.33 & 0.64 & -0.12 & 0.06 & 0.43 & -0.08 & 0.08 \\
\hline Standard length & 0.43 & -0.48 & -0.26 & -0.14 & 0.23 & 0.08 & -0.29 & 0.23 & 0.55 \\
\hline Number of pods per plant & 0.24 & -0.60 & 0.53 & 0.40 & 0.00 & 0.01 & 0.33 & -0.12 & -0.07 \\
\hline Pods: Flower ratio & -0.09 & -0.51 & 0.49 & -0.41 & 0.14 & -0.36 & -0.05 & -0.08 & -0.40 \\
\hline Pod Length & 0.79 & 0.37 & -0.40 & -0.08 & 0.14 & -0.01 & 0.09 & -0.08 & -0.17 \\
\hline No. of seeds / pod & 0.72 & 0.04 & -0.34 & -0.07 & -0.15 & -0.27 & 0.44 & -0.23 & 0.14 \\
\hline seed density & -0.69 & -0.39 & 0.27 & 0.31 & -0.22 & -0.11 & 0.08 & -0.03 & 0.36 \\
\hline Seed length & 0.96 & 0.00 & 0.08 & 0.11 & 0.22 & 0.08 & 0.03 & 0.01 & -0.04 \\
\hline Seed width & 0.94 & 0.10 & 0.23 & -0.03 & 0.17 & -0.14 & -0.08 & 0.00 & -0.03 \\
\hline Seed thickness & 0.75 & 0.59 & 0.12 & 0.24 & 0.01 & 0.03 & 0.03 & 0.17 & -0.03 \\
\hline Seeds shape ratio & 0.54 & -0.32 & -0.21 & 0.35 & 0.25 & 0.57 & 0.24 & 0.05 & -0.03 \\
\hline weight of 100 seeds & 0.82 & 0.21 & -0.14 & -0.09 & 0.03 & -0.45 & -0.21 & -0.04 & -0.03 \\
\hline Eigenvalue & 12.35 & 7.10 & 5.28 & 4.40 & 3.85 & 2.49 & 1.47 & 1.10 & 0.96 \\
\hline Variability (\%) & 31.65 & 18.21 & 13.54 & 11.29 & 9.88 & 6.38 & 3.78 & 2.81 & 2.46 \\
\hline Cumulative \% & 31.65 & 49.86 & 63.40 & 74.69 & 84.57 & 90.95 & 94.73 & 97.54 & 100.0 \\
\hline \multicolumn{4}{|c|}{$\begin{array}{l}\text { For getting the linkage among the studied accessions } \\
\text { and the most useful morphological attributes, the matrix } \\
\text { was standardized, and coordinates were computed for Bi- } \\
\text { plot mapping using perceptual mapping (PERMAP) as } \\
\text { shown in Figure (1). }\end{array}$} & \multicolumn{6}{|c|}{$\begin{array}{l}\text { separate radiata (accessions } 1 \text { and 2) in a group. } \\
\text { Meanwhile, the rest of the unguiculata accessions are } \\
\text { further fell into two groups. The traits of seed thickness, } \\
\text { seed crowding, pod length, testa texture, the weight of } \\
100 \text {-seeds, and stipule ratio split the accessions ( } 6 \text { and } 4 \text { ) } \\
\text { in a group, whereas the rest of the accessions were fell } \\
\text { into one group. }\end{array}$} \\
\hline
\end{tabular}

PERMAP-Biplot shows that the attributes of plant hairiness, stipule length, flower color, and a number of 
Biplot (axes F1 and F2: $49.86 \%$ )

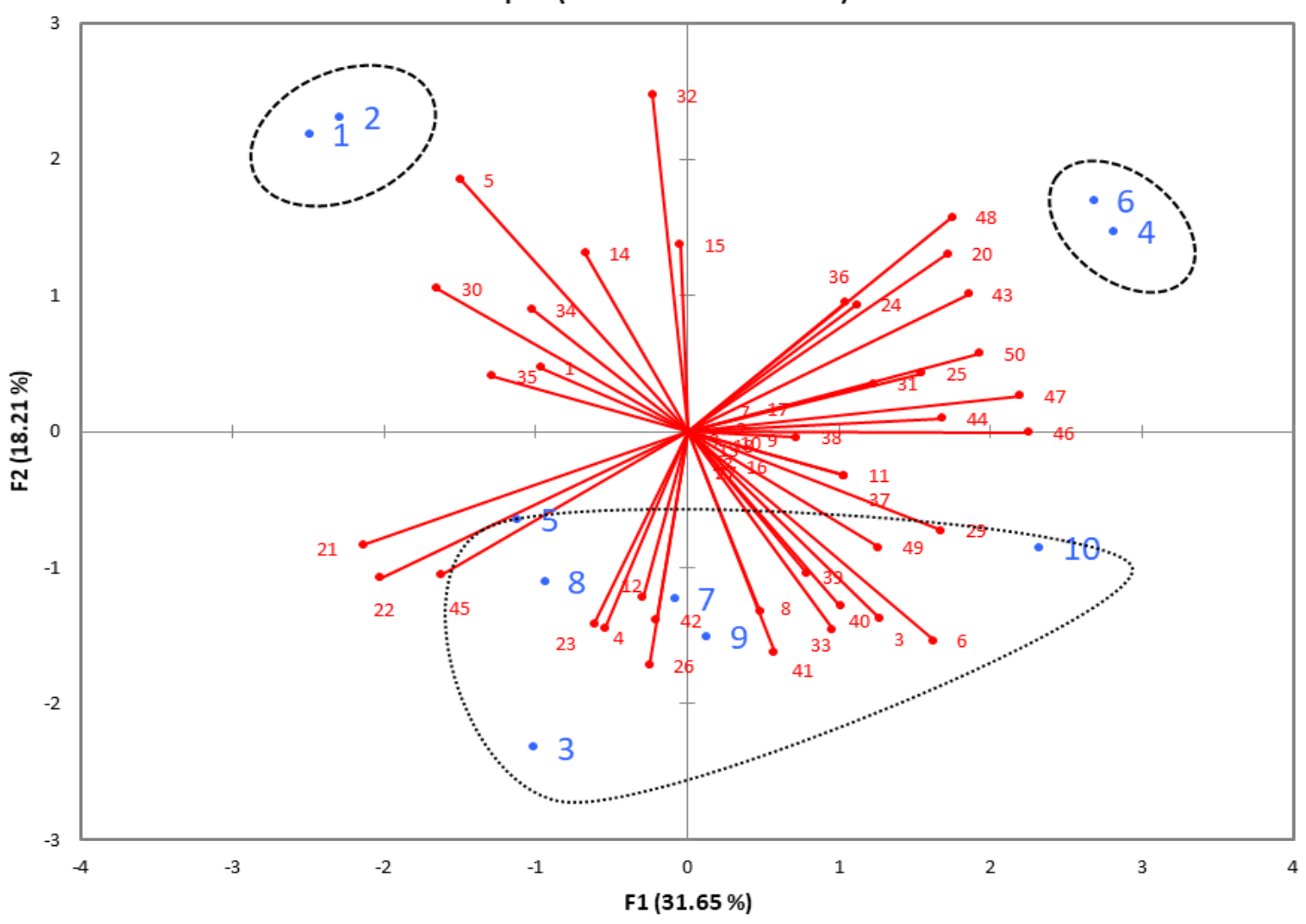

Figure (1): Perceptual mapping (Bi-plot) of the studied accessions of genus Vigna (Table 1) for morphological attributes Table (3 and 4).

\subsection{Genetic diversity among Vigna accessions:}

To find more identification among accessions, they were analyzed by the PCR-based marker technique, SSR. The SSR markers employed revealed a total of 64 alleles ranging from 9 to 3 alleles with $51.32 \%$ of polymorphism and an average of 6.11 loci by the marker. Table 6 summarizes the data obtained for all the analyzed loci. The polymorphism percentages ranged from $11.11 \%$ for EH09 to $75 \%$ for $\mathrm{EH} 10$.

The slight difference between mean $\mathrm{H}_{\mathrm{o}}$ compared to the $\mathrm{H}_{\mathrm{e}}$ probably due to one or more reasons. This might reflect small inbreeding and selection against heterozygotes. The markers used might also back to the observed heterozygosity on account of the non-detection of homozygotes because of the null alleles. The $\mathrm{H}_{\mathrm{o}}$ values varied from 0.0 to 0.3 , with an average value of 0.1 . The highest $\mathrm{H}_{0}$ was 0.3 for EH05 and EH06. The Major PIC $\left(\mathrm{H}_{\mathrm{e}}\right)$ value was 0.86 for EH08 and the minor value $(0.62)$ for EH03; with an average PIC of 0.67. MI values oscillated from 0.85 for EH10 to 13.12 for EH06 primer, with a mean of 5.73. The Shannon's index (I) average was 1.63 for all primers, the lesser value was EH03 (1.03), and the major was 2.10 (EH08). The most informative primers for this data set were EH03, EH09, EH06 and EH07, while the primers EH10, EH02 and EH08 were less informative ones. The effective number of alleles $\left(\mathrm{N}_{\mathrm{e}}\right)$ is a reciprocal of gene homozygosity (Hartl and Clark 1997). The effective number of alleles (ENA) used to corollary the $\mathrm{H}_{\mathrm{e}}$ (when heterozygosity is high, and ENA will be highest). $\mathrm{N}_{\mathrm{e}}$ ranged from 2.6 for EH03 to 7.4 for EH08 with an average of 4.9 per loci. Markers attributes like $\mathrm{I}, \mathrm{H}_{\mathrm{e}}$ and MI have been used in different studies to evaluate the informative or discriminatory power in the primer combination in genetic diversity studies (Tatikonda et al. 2009).

The slight difference between mean $\mathrm{H}_{0}$ compared to the $\mathrm{H}_{\mathrm{e}}$ probably due to one or more reasons. This mirrors small inbreeding, selection against heterozygotes. This marker might naturally back to the $\mathrm{H}_{\mathrm{o}}$ by means of the non-detection of homozygotes due to the null alleles. The $\mathrm{H}_{0}$ values varied from 0.0 to 0.3 , with an average value of 0.1 . The highest $\mathrm{H}_{0}$ was 0.3 for EH05 and EH06, whereas the Major PIC $\left(\mathrm{H}_{\mathrm{e}}\right)$ value was 0.86 for EH08 and a minor value (0.62) for EH03; with an average PIC of 0.67 . MI values oscillated from 0.85 for EH10 to 13.12 for EH06 primer, with a mean of 5.73. The Shannon's index (I) average was 1.63 for all primers, the lesser value was EH03 (1.03), and the major was 2.10 (EH08). The most informative primers for this data set were EH03, EH09, EH06 and EH07, while the primers EH10, EH02 and EH08 were less informative ones. The $\mathrm{N}_{\mathrm{e}}$ is a reciprocal of gene homozygosity (Hartl and Clark 1997). The $\mathrm{N}_{\mathrm{e}}$ used to corollary the $\mathrm{H}_{\mathrm{e}}$ (when heterozygosity is high, ENA will be highest). The $\mathrm{N}_{\mathrm{e}}$ ranged from 2.6 for EH03 to 7.4 for EH08 with an average of 4.9 per loci. Markers attributes like $\mathrm{I}, \mathrm{H}_{\mathrm{e}}$ and MI have been used in different studies to evaluate the informative or discriminatory power in the primer combination in genetic diversity studies (Tatikonda et al. 2009). 
Table 6. Details of marker parameters estimated for SSR markers used in Vigna accessions under study.

\begin{tabular}{|c|c|c|c|c|c|c|c|c|c|c|}
\hline Marker & Size(bp) & $\mathrm{Na}$ & $\mathrm{PB}$ & $\mathrm{P} \%$ & $\mathrm{~N}_{\mathrm{e}}$ & $\mathrm{H}_{\mathrm{o}}$ & $\mathrm{H}_{\mathrm{e}}$ & EMR & MI & I \\
\hline Eh01 & $149-181$ & 4 & 2 & 50 & 2.8 & 0.0 & 0.64 & 4 & 2.56 & 1.28 \\
\hline Eh02 & $130-207$ & 7 & 2 & 28.57 & 5. 6 & 0.0 & 0.82 & 4 & 3.28 & 1.83 \\
\hline Eh03 & $464-504$ & 3 & 3 & 100 & 2.6 & 0.0 & 0.62 & 9 & 5.58 & 1.03 \\
\hline Eh04 & $155-197$ & 7 & 3 & 42.86 & 6.3 & 0.0 & 0.84 & 9 & 7.56 & 1.89 \\
\hline Eh05 & $350-679$ & 8 & 2 & 25 & 5. 3 & 0.3 & 0.81 & 4 & 3.24 & 1.85 \\
\hline Eh06 & $344-540$ & 7 & 4 & 57.14 & 5.4 & 0.3 & 0.82 & 16 & 13.12 & 1.81 \\
\hline Eh07 & $354-563$ & 6 & 3 & 50 & 4.4 & 0.1 & 0.77 & 9 & 7.02 & 1.62 \\
\hline Eh08 & $247-477$ & 9 & 3 & 33.33 & 7.4 & 0.2 & 0.86 & 9 & 7.83 & 2.10 \\
\hline Eh09 & 122-135 & 4 & 3 & 75 & 3.3 & 0.0 & 0.70 & 9 & 6.3 & 1.28 \\
\hline Eh10 & 104-189 & 9 & 1 & 11.11 & 6.4 & 0.2 & 0.84 & 1 & 0.85 & 2.04 \\
\hline Average & & 6.11 & 2.78 & 51.32 & 4.90 & 0.10 & 0.76 & 7.4 & 5.734 & 1.63 \\
\hline
\end{tabular}

$\mathrm{Na}=$ no. of alleles; $\mathrm{PB}=$ no. of polymorphic band; $\mathrm{P} \%=$ polymorphism; $\mathrm{Ne}=$ no. effective alleles; $\mathrm{H}_{\mathrm{o}}=$ observed heterozygosity; $\mathrm{H}_{\mathrm{e}}=$ expected heterozygosity; EMR= effective multiplex ratio; $\mathrm{MI}=$ marker index; I= Shannon informative index.

The SSRs are turning out to be the marker of choice as a result of their high polymorphism and repetitions in the genome. Great efforts are recently powerful to the development of SSR markers applied with various species. In mungbean, polymorphic SSR markers were published by various researchers (Gwag et al. 2006; Somta et al. 2008; Kumar et al. 2002 a and b).

In a study by Somta et al (2008), more than 200 primer pairs while amplifying SSRs were tested for polymorphism among 17 mungbean accessions, however, only $12(5.7 \%)$ primer pairs were polymorphic. Tangphatsornruang et al (2009) assessed 60 polymorphic SSRs. In the mungbean, the number of SSRs reported is not enough for studying genetic diversity with high levels of polymorphism. There is an elementary need to raise the number of SSR polymorphism for genetic mapping and marker-assisted improvement in mungbean. The development of SSRs is a costly and time-consuming endeavor. The SSR development takes in the construction of SSR-enriched libraries, cloning and sequencing, which is costly and labor-intensive (Yu et al. 2009). In this work, the SSR markers showed a high percentage of polymorphism, and it could be useful for DNA and genomic fingerprinting. It may be due to the highly polymorphic, abundant nature of the microsatellites due to The details of SCoT primer parameters data are shown in Table (7). The implied seventeen SCoT-primers showed a total of 153 amplified bands (ranged from 4 to 14 bands) with 69.93\% of polymorphism. The polymorphism percentages ranged to $33.33 \%$ for SCoT-12 to $91.67 \%$ for SCoT-02. The variation between the averages of $H_{o}$ compared to the $H_{e}$ probably be causing one or more reasons. This difference might reflect the nature of markers used, inbreeding and/or selection against heterozygotes. The $H_{o}$ values varied from 0.11 to 0.24 , with an average value of 0.19 . The highest $H_{o}$ was 0.25 for SCoT-03 following by 0.24 for SCoT-02, SCoT-04 and SCoT-13 primers. While the Major value of a PIC was 0.34 for SCoT-02 and the lowest value was 0.12 for SCoT12; with $P I C$ average of 0.25 . The $u H_{e}$ oscillated from 0.13 for SCoT-12 to 0.36 for SCoT-02; it was an average mean of 0.27 . The Inbreeding Coefficient (Fixation Index, F) ranged from -0.33 to 0.55 for SCoT-13 and SCoT-48 respectively, with the total average being 0.21 .

The higher attributes of marker parameter, the $M I$ value was an average of 0.25 and ranged from 0.01 for SCoT-12 to 0.82 for SCoT-02 primer. The average of Shannon Index $(I)$ was 0.39 for all primers, the lesser value was to SCoT-12 (0.18), and the major was 0.51 (SCoT-02). 
Table (7). Details of marker parameters estimated for SCoT primers.

\begin{tabular}{|c|c|c|c|c|c|c|c|c|c|c|c|c|c|}
\hline Primers & $\mathrm{N}_{\mathrm{b}}$ & $\mathrm{N}_{\mathrm{e}}$ & $\mathrm{PB}$ & $\mathrm{P} \%$ & PIC & EMR & MI & $\mathrm{RP}$ & I & $\mathrm{H}_{\mathrm{o}}$ & $\mathrm{H}_{\mathrm{e}}$ & $\mathrm{uH}_{\mathrm{e}}$ & $\mathrm{F}$ \\
\hline SCoT-02 & 12 & 1.56 & 11 & 91.67 & 0.34 & 2.42 & 0.82 & 8.0 & 0.51 & 0.24 & 0.34 & 0.36 & 0.29 \\
\hline SCoT-03 & 6 & 1.52 & 5 & 83.33 & 0.31 & 1.04 & 0.33 & 3.6 & 0.48 & 0.25 & 0.31 & 0.33 & 0.20 \\
\hline SCoT-34 & 5 & 1.36 & 4 & 80.00 & 0.23 & 0.64 & 0.15 & 1.8 & 0.36 & 0.20 & 0.23 & 0.24 & 0.13 \\
\hline SCoT-28 & 7 & 1.40 & 5 & 71.43 & 0.25 & 0.81 & 0.20 & 3.4 & 0.39 & 0.23 & 0.25 & 0.26 & 0.10 \\
\hline SCoT-48 & 4 & 1.58 & 3 & 75.00 & 0.32 & 0.32 & 0.10 & 3.2 & 0.46 & 0.14 & 0.32 & 0.33 & 0.55 \\
\hline SCoT-35 & 10 & 1.54 & 8 & 80.00 & 0.32 & 1.49 & 0.48 & 5.8 & 0.49 & 0.23 & 0.32 & 0.34 & 0.28 \\
\hline SCoT-05 & 7 & 1.38 & 5 & 71.43 & 0.24 & 0.81 & 0.19 & 3.0 & 0.37 & 0.23 & 0.24 & 0.25 & 0.05 \\
\hline SCoT-06 & 10 & 1.49 & 7 & 70.00 & 0.28 & 0.70 & 0.20 & 4.4 & 0.41 & 0.14 & 0.28 & 0.30 & 0.49 \\
\hline SCoT-13 & 10 & 1.27 & 6 & 60.00 & 0.18 & 0.88 & 0.16 & 3.8 & 0.30 & 0.24 & 0.18 & 0.19 & -0.33 \\
\hline SCoT-14 & 14 & 1.44 & 9 & 64.29 & 0.27 & 1.14 & 0.30 & 6.2 & 0.41 & 0.20 & 0.27 & 0.28 & 0.26 \\
\hline SCoT-16 & 10 & 1.36 & 7 & 70.00 & 0.23 & 0.96 & 0.22 & 3.8 & 0.36 & 0.20 & 0.23 & 0.24 & 0.15 \\
\hline SCoT-24 & 8 & 1.50 & 6 & 75.00 & 0.28 & 0.73 & 0.21 & 3.8 & 0.42 & 0.16 & 0.28 & 0.30 & 0.42 \\
\hline Total & 153 & 24.1 & 107 & 69.93 & 4.3 & 0.94 & 4.32 & 68.6 & 6.6 & 3.3 & 4.3 & 4.55 & 3.51 \\
\hline Average & 9 & 1.42 & 6.3 & & 0.25 & 0.94 & 0.25 & 4.04 & 0.39 & 0.19 & 0.25 & 0.27 & 0.21 \\
\hline
\end{tabular}

$\mathrm{N}_{\mathrm{b}}=$ no. of alleles; $\mathrm{Ne}=$ no. effective alleles; $\mathrm{PB}=$ no. of polymorphic band; $\mathrm{P} \%=$ polymorphism; PIC= polymorphic information content; $\mathrm{EMR}=$ effective multiplex ratio; $\mathrm{MI}=$ marker index; $\mathrm{I}=$ Shannon informative index; $\mathrm{H}_{\mathrm{o}}=$ observed heterozygosity; $\mathrm{H}_{\mathrm{e}}=$ expected heterozygosity; $\mathrm{uH}_{\mathrm{e}}=$ unbiased heterozygosity; $\mathrm{F}=$ fixation index

The Resolving Power (RP) was an average of 4.04; oscillated from 1.0 of SCoT-12 primer to 8.0 of SCoT-02 primer. The effective number of alleles $\left(N_{e}\right)$ is a reciprocal of gene homozygosity (Hartl and Clark 1997). The effective number of alleles (ENA) used to corollary the $H_{e}$ (when heterozygosity is high, ENA will be highest). $N_{e}$ ranged from 1.22 for SCoT-12 primer to 1.58 for SCoT-48 primer with the mean of 1.42 per primer.

These bands can be considered as potential markers to identify accessions of cowpea or maybe more useful when converted into a simple sequence PCR-based marker that can be used for large-scale screening of accessions. These molecular markers could assess to the acceleration of detection to Vigna accessions on the bases of molecular markers at laboratory conditions only with comparison to field screening, which is very difficult and less accurate. In another species, Huq et al (2009) characterized 60 genotypes of $C$. olitorius and C. capsularis using SSR marker attained a high polymorphism value of $92.2 \%$, with a total of 171 different alleles amplified by 27 primer pairs.

\subsection{Similarity and genetic distance between accessions}

The similarity matrices by Jaccard (1908) coefficient among accessions of cowpea basing on SSR analysis are given in Table 8 . The highest values of similarity were recorded between accession 7 and $9(0.86)$. On the other hand, between accessions 1 and 6 and accession 1 and 8 (0.29) were recorded the lowest similarity.

The similarity matrices generated by the SCoT marker among accessions showed that the highest similarity value was recorded between accession 5 and 4 and between accession 9 and 6 (0.69). On the other hand, between accessions 2 and 6 the lowest similarity recorded was (0.39), whereas investigation derived from both markers showed the highest similarity was 0.69 between accession 1 and 2, and 0.66 between accession 8 and 9. On the other hand, the lowest value of similarity scored 0.11 among accession 2 and 6. 
Table (8): Similarity matrix among ten Vigna accessions based on markers used.

\begin{tabular}{|c|c|c|c|c|c|c|c|c|c|c|}
\hline Acc. & 1 & 2 & 3 & 4 & 5 & 6 & 7 & 8 & 9 & 10 \\
\hline \multicolumn{11}{|l|}{ SSR } \\
\hline 1 & 1.00 & & & & & & & & & \\
\hline 2 & 0.83 & 1.00 & & & & & & & & \\
\hline 3 & 0.37 & 0.30 & 1.00 & & & & & & & \\
\hline 4 & 0.37 & 0.30 & 0.79 & 1.00 & & & & & & \\
\hline 5 & 0.45 & 0.38 & 0.56 & 0.59 & 1.00 & & & & & \\
\hline 6 & 0.29 & 0.31 & 0.58 & 0.48 & 0.50 & 1.00 & & & & \\
\hline 7 & 0.35 & 0.38 & 0.68 & 0.75 & 0.57 & 0.59 & 1.00 & & & \\
\hline 8 & 0.29 & 0.31 & 0.57 & 0.61 & 0.55 & 0.57 & 0.80 & 1.00 & & \\
\hline 9 & 0.30 & 0.32 & 0.68 & 0.65 & 0.50 & 0.52 & 0.86 & 0.80 & 1.00 & \\
\hline 10 & 0.34 & 0.37 & 0.48 & 0.44 & 0.46 & 0.65 & 0.55 & 0.52 & 0.55 & 1.00 \\
\hline \multicolumn{11}{|c|}{ SCoT } \\
\hline 1 & 1.00 & & & & & & & & & \\
\hline 2 & 0.66 & 1.00 & & & & & & & & \\
\hline 3 & 0.43 & 0.49 & 1.00 & & & & & & & \\
\hline 4 & 0.44 & 0.42 & 0.63 & 1.00 & & & & & & \\
\hline 5 & 0.44 & 0.41 & 0.53 & 0.69 & 1.00 & & & & & \\
\hline 6 & 0.50 & 0.39 & 0.44 & 0.60 & 0.68 & 1.00 & & & & \\
\hline 7 & 0.48 & 0.44 & 0.50 & 0.52 & 0.58 & 0.58 & 1.00 & & & \\
\hline 8 & 0.48 & 0.45 & 0.51 & 0.51 & 0.48 & 0.52 & 0.64 & 1.00 & & \\
\hline 9 & 0.44 & 0.42 & 0.50 & 0.55 & 0.61 & 0.69 & 0.67 & 0.68 & 1.00 & \\
\hline 10 & 0.47 & 0.44 & 0.51 & 0.51 & 0.51 & 0.50 & 0.57 & 0.67 & 0.67 & 1.00 \\
\hline \multicolumn{11}{|c|}{ Both markers } \\
\hline 1 & 1.00 & & & & & & & & & \\
\hline 2 & 0.69 & 1.00 & & & & & & & & \\
\hline 3 & 0.18 & 0.29 & 1.00 & & & & & & & \\
\hline 4 & 0.22 & 0.20 & 0.56 & 1.00 & & & & & & \\
\hline 5 & 0.22 & 0.19 & 0.31 & 0.58 & 1.00 & & & & & \\
\hline 6 & 0.23 & 0.11 & 0.16 & 0.41 & 0.50 & 1.00 & & & & \\
\hline 7 & 0.25 & 0.25 & 0.30 & 0.36 & 0.38 & 0.38 & 1.00 & & & \\
\hline 8 & 0.28 & 0.28 & 0.37 & 0.40 & 0.31 & 0.38 & 0.60 & 1.00 & & \\
\hline 9 & 0.19 & 0.20 & 0.32 & 0.41 & 0.44 & 0.54 & 0.60 & 0.66 & 1.00 & \\
\hline 10 & 0.27 & 0.27 & 0.32 & 0.33 & 0.30 & 0.35 & 0.42 & 0.59 & 0.57 & 1.00 \\
\hline
\end{tabular}

Basing on Nei and Li (1979) coefficient, the phenogram generated by UPGMA cluster analysis showed the clustering of ten accessions of Vigna (Fig. 2). Investigations derived from the SSR marker (Fig. 2a) are divided into two groups at a distance of 0.338 . The first one includes accession 1 and 2. The second group is divided into two sub-groups at a distance of 0.519 ; the first subgroup includes accession 6 and 10. Whereas, the second subgroup is further divided into sub-sub-groups at a distance of 0.554; one of them consists of accession 5 only, and the other is divided into two sub-sub sub-group at a distance of 0.658 . One has accession 4 and 3 , whereas the second is divided into sub-sub-sub-sub-group at a

distance of 0.826 . The first one includes accession 8 only; the second one consists of accession 7 and 9 .

Data generated by SCoT analysis (Fig. 2b) are divided into two groups at a distance of 0.446 . The first one includes accession 1 and 2 only. The second group is divided into two sub-groups at a distance of 0.534 . The first sub-group was separated into two sub-sub-group at a distance of 0.579; one includes accession 3 only and the other one consists of accessions 4 and 5 . Whereas, the second sub-group is further divided into sub-sub-groups at distance of 0.598; one of them consists of accessions 8 and 10 only, and the other is divided into two sub-sub-subgroups at distance of 0.625 . One has accession 7only, whereas the second one has accessions 6 and 9 . 

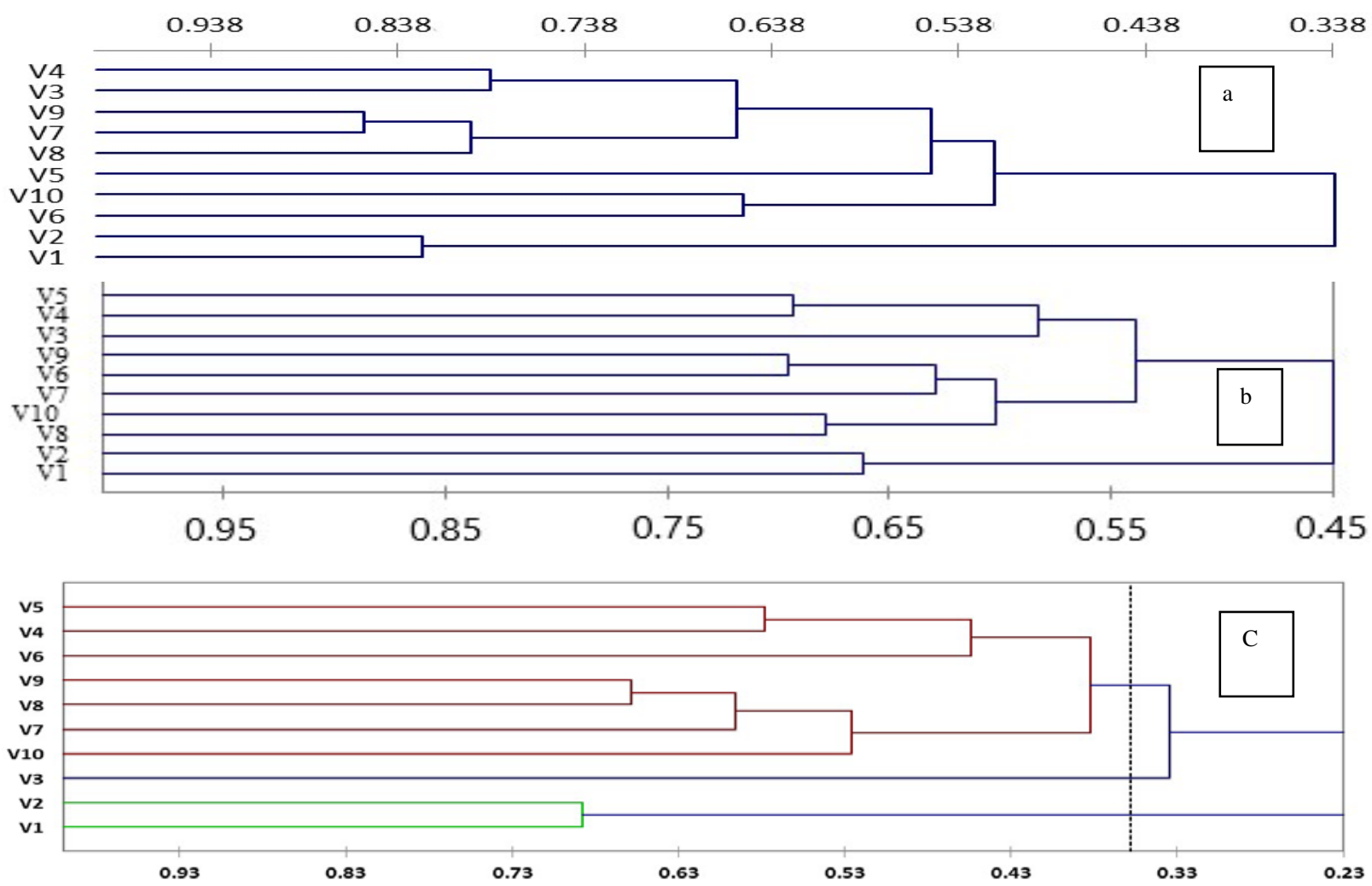

Figure (2): Dendrogram generated by UPGMA-cluster analysis basing on Nei and Li (1979) coefficient.

It is noted from Figure 2c the data based on both markers are separated into two main groups in three classes of objects at a distance of 0.227 ; the first group includes accession 1 and 2 only, while the second group was divided into two groups at a distance of 0.334 ; one of them consists of accession 3 whereas the other one is further separated into sub-sub groups at 0.382 . Each subsub group is further divided into two sub-sub-sub groups. One includes accession 6 only and accessions 4 and 5 at a distance of 0.454 . Another one involves accession 10 at a distance of 0.5255 and the rest separated at a distance of 0.578 . The distance between the central objects of all classes is presented in Table 9. Data showed the first central-class includes two objects which be accessions 1 and 2; the second class has one object (accession 3 only); whereas the last class consists of seven objects (the rest accessions). The highest distance is recorded between classes 1 and 2 (9.00), while the lowest value was between classes 2 and 3 (8.12); whereas the variance within class recorded 15.00, 26.7 and 0.00 for class 1,3 and 2, respectively with an average distance ranged from 2.7 to 4.8 .

Table 9. Distances between the central objects regenerated by UPGMA cluster analysis.

\begin{tabular}{llll}
\hline Class & 1 & 2 & 3 \\
\hline 1 & 0.00 & & \\
2 & 9.00 & 0.00 & \\
3 & 8.89 & 8.12 & 0.00 \\
\hline Number of objects & 2 & 1 & 7 \\
Within-class variance & 15.00 & 0.00 & 26.67 \\
Average distance to centroid & 2.74 & 0.00 & 4.77 \\
\hline
\end{tabular}

The choice of molecular markers used in identification when first being selected is very critical to consider. Both markers have great potential in accession identification and can reproduce polymorphisms. The results indicated that the two types of markers were able to effectively identify Vigna accessions through DNA assays. Both markers have a high ability to identify specific accession. Therefore, this approach was able to successfully distinguish between the tested germplasm, and we were able to construct unique DNA profiles of each accession for future use. The present study has revealed a broad genetic base in Vigna species and suggests the taxonomist review the genotypes using molecular markers. This study would help in the consideration of molecular fingerprinting for germplasm conservation, rectification, purification, and identification of germplasm. This indicates that the Vigna species has a broad sense of genetic diversity and allocates in agroclimatic regions.

\section{Conclusion}

Evaluation of genetic diversity helps in the identification of diverse germplasm that can be utilized by breeding for creating the desired variation. They demand the immediate attention of plant breeders. The available elite accessions are necessarily the products of selection from a few common accessions. For any meaningful plant breeding program, accurate estimates of genetic 
diversity and partitioning within and between gene pools are important considerations. The scope for characterizing genetic diversity in cowpea at different levels presents immense opportunities.

Information about the degree and distribution of genetic variation and relationships among breeding materials has a significant effect on crop improvement. In the present study, the used techniques were an efficiency to estimate the genetic variation. Our data indicated that the used markers could effectively identify cowpea accessions because of morphological, agronomical and molecular characterization which give us more insights into the selection of a desirable accession for Vigna genetic improvement. In addition, the results revealed a high genetic variation among tested accessions, which can be used in cowpea breeding programs and improvement basing on the overall aims. Our study would help in the reflection of molecular fingerprinting for germplasm conservation, rectification, purification, and identification of germplasm for the genetic diversity of Vigna species and its distribution across agroclimatic districts. Thus, that should focus on collecting more landrace collections, as well as obtaining more genetic information for the improvement and development of new cultivars.

\section{Acknowledgments}

Authors acknowledge Dr. Shafiq I. Darweesh, researcher of Genome mapping, Agricultural Genetic Engineering Research Institute (AGERI), Agricultural Research Center (ARC), for his help and guidance in conducting molecular section, especially CAPS-marker. We wish also to express thanks to the Taxonomy Dept., especially Prof. Dr. Reda M. Rizk, director of Taxonomy Dept. National Gene Bank (NGB), Agricultural Research Center (ARC), Egypt, for helping us to identify accessions and completing this study. We acknowledge and appreciate the comments of anonymous reviewers and technical editors of the Journal.

\section{References}

Alisa Kongjaimun, Akito Kaga, Norihiko Norihiko, Prakit Somta, Takehiko Shimizu, Yujian Shu, Takehisa Isemura, Duncan A. Vaughan, and Peerasak Srinives

Al-Qurainy F, Khan S, Nadeem M and Tarroum M. 2015. SCoT marker for the assessment of genetic diversity in Saudi Arabian date palm cultivars. Pak J. Bot., 47(2):637-643.

Amirbakhtiar N and Sorkheh K. 2015. Analysis of diversity and relationships among wild Pistacia species using Start Codon Targeted (SCoT) markers. $1^{\text {st }}$ Int and $9^{\text {th }}$ Int. Cong. Islamic Republic of Iran, May 24-26, Shahid Beheshti University, Tehran, Iran p:1-4.

Anderson JA, Churchill GA, Autrique JE, Tanksley SD and Sorrells ME. 1993. Optimizing parental selection for geneticlinkage maps. Genome, 36(1):181-186.

Collard BCY and Mackill DJ. 2009. Start Codon Targeted (SCoT) Polymorphism: a simple, novel DNA marker technique for generating gene-targeted markers in plants. Plant Mol. Biol. Rep., 27:86-93.

Dachapak S, Somta P, Poonchaivilaisak S, Yimram T, Srinives P. 2017. Genetic diversity and structure of the zombie pea (Vigna vexillate (L.) A. Rich) gene pool based on SSR marker analysis. Genetica, 145:189-200.

Gwag J, Chung J, Chung H, Lee J, Ma K, Dixit A, Park Y, Cho E, Kim T and Lee S. 2006. Characterization of new microsatellite markers in mung bean, Vigna radiate (L.). Mol. Ecol. Notes, 6: 1132-1134.

Hartl DL and Clark AG (1997) Principles of Population Genetics. $3^{\text {rd }}$ ed., Sinauer Associates, Inc., Sunderland, MA, USA.

Heikrujam M, Kumar J and Agrawal V. 2015 Genetic diversity analysis among male and female Jojoba genotypes employing gene targeted molecular markers, start codon targeted (SCoT) polymorphism and CAAT box-derived polymorphism (CBDP) markers. Meta Gene, 5: 90-97.

Hernandez P, Laurie DA, Martin A and Snape JW. 2002. Utility of barley and wheat simple sequence repeat (SSR) markers got genetic analysis of Hordeum chilense and tritodeum. Theor. Appl. Genet., 104:735-739.

Huq S, Islam MDS, Sajib AA, Ashraf N, Haque S and Khan H. 2009. Genetic diversity and relationships in jute (Corchorus spp.) revealed by SSR markers. Bangladesh J. Bot., 38(2):153-161.

IBPGR 1983. INTERNATIONAL BOARD FORPLANT GENETIC RESOURCES. Descriptor for cowpea. IBPGR secretariat, Rome.

IPGRI 1994. INTERNATIONAL PLANT GENETIC RESOURCES INSTITUTE. Genebank Standards. Food and Agriculture Organization of the United Nations, Rome, Rome.

Jaccard P. 1908 Nouvelles recherces sur la distribution florale. Bull. Soc. Vaudoise Sci. Nat., 44: 223-270.

Jiang QQ, Long GY, Li WW and Deng ZN. 2011. Identification of genetic variation in Citrus sinensis from Hunan on start codon targeted polymorphism. Agric. Sci. Technol., 12(11):1594-1599.

Johnson DE (1998) Applied multivariate methods for data analysis. Duxbury Press, New York.

Karuniawan A, Iswandi A, Kale PR, Heinzemann J and Grüneberg WJ. 2006 Vigna vexillate (L.) A. Rich. Cultivated as a root crop in Bali and Timor. Genet. Resour. Crop Evol., 53(1):213-217.

Kongjaimun A, Kaga A, Norihiko N, Somta P, Shimizu T, Shu Y, Isemura T, Vaughan DA, and Srinives P. 2012 An SSR-based linkage map of yardlong bean (Vigna unguiculata (L.) Walp. subsp. unguiculata Sesquipedalis Group) and QTL analysis of pod length. Genome, 55:81-92.

Kumar SV, Tan SG, Quah SC and Yusoff K. 2002a. Isolation and characterization of seven tetranucleotide microsatellite loci in mungbean, Vigna radiata. Mol Ecol. Notes, 2:293-295.

Kumar SV, Tan SG, Quah SC, Yusoff K. 2002b. Isolation of microsatellite markers in mungbean, Vigna radiata. Mol. Ecol. Notes, 2:96-98.

Leo, C., He XH, Chen H, SJO, Gao MP, Brown JS, Tondo CT and Schnell RJ. 2011. Genetic diversity of mango cultivars estimated using SCoT and ISSR markers. Biochem. Syst. Ecol. 39:676-684.

Li CD, Fatokun CA, Ubi B, Singh BB and Scoles GJ. 2001. Determining genetic similarities and relationships among cowpea breeding lines and cultivars by microsatellite markers. Crop Sci, 41(1):189-197.

Maréchal R, Mascherpa JM, Stainer F. 1978. Etude taxonomique d'un groupecomplexe d'speces des genresPhaseolus et Vigna (Papilionaceae) sur labase de donnees morphologiques et polliniques, traitees par l'analyse informatique. Boissiera $\mathbf{2 8}$. 
Mulpuri S, Muddanuru T and Francis G. 2013. Start codon targeted (SCoT) polymorphism in toxic and non-toxic accessions of Jatropha curcas L. and development of a codominant SCAR marker. Plant Sci., 207: 117-127.

Nei M and Li M. 1979. Mathematical model for studying genetic variation in terms of restriction endonucleases. Proc. Nat. Acad. Sci. USA, 76:5269-5273.

Norihiko T, Kaga A, Isemura T, Vaughan D, Srinives P, Somta P, Thadavong S, Bounphanousay C, Kanyavong K, Inthapanya P, Pandiyan M, Senthil N, Ramamoorthi N, Jaiwal PK, Jing T, Umezawa K, Yokoyama T. 2010. Vigna genetic resources. Proceeding of the14th NIAS international workshop on Genetic Resources, Genetic and Comparative Genomics of Legumes (Glycine and Vigna). pp.11-21.

Norihiko T, Naito K, Kaga A, Sakai H, Isemura T, Ogiso-Tanaka E, Iseki K and Takahashi Y. 2014. Evolution, domestication and neo-domestication of the genus Vigna. Plant Genet. Resour., 12(1):168-171.

Ogunkanmi LA, Ogundipe OT, Ng NQ and Fatokun CA. 2008. Genetic diversity in wild of cowpea (Vigna unguiculata) as revealed by simple sequence repeats (SSR) markers. J Food, Agric \& Environ, 8:263-268.

Ojeda FS, Hoc PS and Garcia MTA. 2013. Morphology of seeds and seedlings of four species of Vigna Savi (Leguminosae, Phaseolinae). Acta Bot. Bras, 27(3):483-489.

Peakall R, Smouse PE (2006). GENALEX 6: genetic analysis in Excel. Population genetic software for teaching and research. Mol. Ecol. Notes, 6:288-295.

Powell W, Marchary GC and Provan J. 1996. Polymorphism revealed by simple sequence repeats. Trends in Plant Science, 1:215-222.

Prevost A and Wilkinson MJ. 1999. A new system of comparing PCR primers applied to ISSR fingerprinting of potato cultivars. Theor. Appl. Genetic, 98:107-112.

Sawant SV, Singh PK, Gupta SK, Madnala R and Tuli R. 1999 Conserved nucleotide sequences in highly expressed genes in plants. J. Genet., 78:123-131.

Selvakumar G and Kumari RU. 2015. Phenotypic Expression in Inter Subspecies Crosses of Cowpea (Vigna unguiculata (L.) Walp.) and Yard Long Bean (Vigna unguiculata (L.) Walp. spp. sesquipedalis). J. Pl. Sci. Res., 31(1):101-108.

Shrivastav A, Babbar A, Prakash A, Tripathi N and Iquebal MA. 2012. Genetics and molecular diversity analysis of chickpea (Cicer arietinum L.) genotypes grown under rice fallow condition. J. Food Leg., 25(2):147-149.
Soliman MI, Rizk, RM, El-Eraky NM. 2008. Cytogenetics comparison of cultivated and wild relatives of genus Vigna in Egypt. CATRINA. 3(1): 61-70.

Somta P, Musch W, Kongsamai B, Chanprame S, Nakasathien S, Toojinda T, Sorajjapinun W, Seehalak W, Tragoonrung S and Srinives P. 2008. New microsatellite markers isolated from mungbean (Vigna radiata (L.) Wilczek). Mol. Ecol. Res., 8:11551157.

Stearn WT. 1973. Botanical Latin. Newton Abbott: David and Charles.

Tangphatsornruang S, Somta P, Uthaipaisanwong P, Chanprasert J, Sangsrakru D, Seehalak W, Sommanas W, Tragoonrung S and Srinives P. 2009. Characterization of microsatellites and gene contents from genome shotgun sequences of mungbean (Vigna radiata (L.) Wilczek). BMC Plant Biol 9:137-147.

Tatikonda L, Wani SP, Kannan S, Beerelli N, Sreedevi TK, Hoisington DA, Devi P and Varshney RK. 2009. AFLP-Based Molecular Characterization of an Elite Germoplasm Collection of Jatropha curcas L. a Biofuel Plant. Plant Sci., 176:505-513.

Varshney RK, Chabane K, Hendre PS, Aggarwal RK and Graner A. 2007. Comparative assessment of EST-SSR, EST-SNP and AFLP markers for evaluation of genetic diversity and conservation of genetic resources using wild, cultivated and elite barleys. Plant Sci., 173:638-649.

Wang XW, Kaga A, Tomooka N and Vaughan DA. 2004. The development of SSR markers by a new method in plants and their application to gene flow studies in azuki bean [Vigna angularis (Willd.) Ohwi \& Ohashi. Theor. Appl. Genet., 109:352-360.

Weber JL and May JL. 1989. Abundant class of human DNA polymorphism which can be types using the polymerase chain reaction. Amer. J. Hum. Genet., 44:388-396.

Yin X, Chasalow SD, Stam PM, Kropff J, Dourleijn CJ, Bos I, Bindraban PS. 2002. Use of component analysis in QTL mapping of complex crop traits: a case study on yield in barley. Plant Breeding, 121(4):314.

Yu J-W, Dixit A, Ma K-H, Chung J-W and Park Y-J. 2009. A study on relative abundance composition and length variation of microsatellites in eighteen underutilized crop species. Genet Res Crop Evol, 56:237-246. 